\title{
AVALIAÇÃO DO ENADE NA ÁREA DE PEDAGOGIA: análises e discussões à luz das diretrizes curriculares de formação do pedagogo
}

\author{
Heloisa Toshie Irie Saito' \\ Marta Quintanilha Gomes 2 \\ Divaneide Lira Lima Paixão ${ }^{3}$ \\ Franciana Carneiro de Castro 4 \\ Silvia Cristina de Souza ${ }^{5}$ \\ Gilmar Barbosa Guedes 6
}

Maria das Graças Medeiros Tavares ${ }^{7}$

\begin{abstract}
RESUMO
Este texto apresenta reflexões da Comissão Assessora de Área de Pedagogia do Enade 2014 acerca da relação entre os conteúdos constantes nas questões do Enade/Pedagogia em 2008, 2011 e 2014 e as Diretrizes Curriculares Nacionais para o Curso de Graduação em Pedagogia/2006. Traz um breve histórico do curso de Pedagogia no Brasil, evidencia as diretrizes de formação do pedagogo, expõe a pesquisa documental como metodologia, a qual utilizou o software Alceste para tratar os dados, cuja análise será exibida na sequência. Constatou-se que essas provas do Enade trazem elementos que revelam a existência de convergência entre a orientação da formação e a avaliação do curso, porém, devido ao contexto amplo de avaliação de política de formação, não é possível verificar, plenamente, todos os elementos constitutivos dessa formação.
\end{abstract}

Palavras-chave: Formação de Professores. Currículo de Pedagogia. Enade.

\footnotetext{
1 Doutora em Educação, Universidade Estadual de Maringá (UEM). Orcid iD: https://orcid.org/0000-0003-1061-5933.E-mail: htisaito@vem.br

2 Doutora em Educação, Universidade Federal de Ciências da Saúde de Porto Alegre (UFCSPA). Orcid iD: https://orcid.org/0000-0001-9320-3277. E-mail: martaqg@ufcspa.edu.br

${ }^{3}$ Doutora em Psicologia, Secretaria de Estado de Educação do Distrito Federal (SEEDF). Orcid iD: https://orcid.org/0000-0002-9703-1609. E-mail: divaneidepaixao@gmail.com

${ }^{4}$ Doutora em Educação Matemática, Universidade Federal do Acre (UFAC). Orcid iD: https://orcid.org/0000-0002-6588-4180. E-mail: francianaccastro@gmail.com

${ }^{5}$ Doutora em Educação, Centro Universitário Toledo de Araçatuba (UNITOLEDO). Orcid iD: https://orcid.org/0000-0002-6220-001 1. E-mail: silvia@toledo.br

${ }^{6}$ Doutor em Educação, Universidade Federal do Rio Grande do Norte (UFRN). Orcid iD: https://orcid.org/0000-0002-3296-4096. E-mail: gbguedes@uol.com.br

${ }^{7}$ Doutora em Educação, Universidade Federal do Estado do Rio de Janeiro (UNIRIO). Orcid iD: https://orcid.org/0000-0002-2182-3319. E-mail: graccatavares@vol.com.br
} 
EVALUATION OF ENADE IN THE AREA OF PEDAGOGY: analyses and discussions in the light of the curriculum guidelines of the pedagogue formation

\begin{abstract}
This paper presents the reflections of the Educational Area of the Advisors Commission of ENADE 2014 about the relationship between the content contained on the issues of ENADE/Pedagogy in the years 2008, 2011 and 2014 with the National Curriculum Guidelines for Undergraduate Course in Pedagogy/2006. Brings a brief history of the Pedagogy course in Brazil, the presentation of teacher's training guidelines, the documental research methodology which used the Alceste software to process the data, and finally, the data analysis. We found that the ENADE exams reveal that there is convergence between the orientation of the training and the evaluation of the course, therefore, due to the wide context of policy formation evaluation, they are not able to fully check all the constituent elements of such training.
\end{abstract}

Keywords: Teacher training. Curriculum of Pedagogy. Enade.

\title{
EVALUACIÓN DEL ENADE EN EL ÁREA DE PEDAGOGÍA: análisis y discusiones a la luz de las directrices curriculares de formación del pedagogo
}

\section{RESUMEN}

Este texto contiene las reflexiones de la Comisión Asesora del Área de Pedagogía del Enade 2014 acerca de la relación entre los contenidos constantes en las cuestiones del Enade/Pedagogía en 2008, 2011 y 2014 y las Directrices Curriculares Nacionales para el Curso de Graduación en Pedagogía/2006. Recupera una breve historia del curso de Pedagogía en Brasil, evidencia las directrices de formación del pedagogo, expone la investigación documental como metodología, la cual utilizó el software Alceste para tratar los datos, cuyo análisis será exhibido en la secuencia. Se ha comprobado que estas pruebas del Enade traen elementos que revelan la convergencia entre la orientación de la formación y la evaluación del curso, pero, debido al amplio contexto de evaluación de la política de formación, no es posible comprobar plenamente todos los elementos constitutivos de dicha formación.

Palabras clave: Formación de profesores. Currículo de Pedagogía. Enade.

\section{INTRODUÇÃO}

No período compreendido entre as décadas de 1970 e de 1990, as transformações econômicas e político-sociais em processo na sociedade capitalista, motivadas pela reestruturação produtiva e pela crise fiscal dos estados nacionais, levaram à necessidade de avaliar as políticas públicas desenvolvidas nas diferentes instâncias federativas, inclusive aquelas 
desenvolvidas para a área educacional. A burocracia estatal nacional, à luz de diretrizes emanadas dos organismos multilaterais mundiais - Banco Mundial, Organização Mundial do Comércio (OMC), Fundo Monetário Internacional (FMI) etc. - e a matiz neoliberal, desencadearam o processo de reforma do Estado com o intuito de modificar o arcabouço legal e as práticas de avaliação. Nesse sentido, objetivou-se avaliar as políticas sociais para encontrar indicadores satisfatórios de eficiência e de eficácia, buscando a performatividade no desenvolvimento das políticas implementadas para os diferentes setores da administração pública.

Essa conjuntura de modificações acarretadas pela reforma do Estado brasileiro induziu governos e sociedade civil a modificarem o ordenamento institucional, o qual ocorreu, inicialmente, por meio da promulgação da Constituição Federal de 1988, cujo Art. 209 passou a regulamentar o funcionamento da educação superior nacional. Além disso, de modo especial, a Lei no 9.394 de 1996, conhecida como Diretrizes e Bases da Educação Nacional (LDB/96), no seu Art. 9.․ inciso VIII, prevê o seguinte: "assegurar processo nacional de avaliação das instituições de educação superior, com a cooperação dos sistemas que tiverem responsabilidade sobre este nível de ensino" (BRASIL, 1996, grifo nosso).

Com o intuito de consubstanciar essas diretrizes constitucionais e a legislação ordinária referida no âmbito do planejamento educacional do Estado, instituiu-se o Plano Nacional de Educação - PNE (2001-2011), que previa a necessidade de avaliar a educação superior. Para tanto, a Meta 6 estabelecia "Institucionalizar um amplo e diversificado sistema de avaliação interna e externa que englobe os setores público e privado, e promova a melhoria da qualidade do ensino, da pesquisa, da extensão e da gestão acadêmica". A Lei no 13.005, de 25 de junho de 2014, que instituiu o PNE (2014-2024), define, na Meta 13, a 'elevação da qualidade da educação superior', notadamente, nas estratégias 13.1 e 13.2, as quais prescrevem, respectivamente, 
fortalecendo as ações de avaliação, regulação e supervisão; [...] ampliar a cobertura do Exame Nacional de Desempenho de Estudantes - ENADE, de modo a ampliar o quantitativo de estudantes e de áreas avaliadas no que diz respeito à aprendizagem resultante da graduação [...] (BRASIL, 2014).

Mesmo considerando essa legislação federal, cabe salientar que os modelos avaliativos assumiram desenhos diferenciados em razão das discussões e dos estudos desencadeados por pesquisadores da área em articulação com os órgãos competentes que avaliam e regulam a educação superior.

No período de 1996 a 2003, os cursos de graduação foram avaliados por meio do Exame Nacional de Cursos (ENC), conhecido como 'Provão', estabelecido pela Lei $n^{\circ} 9.131 / 1995$, cujo objetivo foi apreender os conhecimentos e as competências adquiridos pelos estudantes que estavam em vias de concluir o curso de graduação. Assim, em 2001, o curso de Pedagogia passou a ser avaliado nessa perspectiva.

Em 2003, a partir da constituição da Comissão Especial de Avaliação da Educação Superior (CEA), houve a análise do processo de avaliação até então estabelecido, revisando os instrumentos e a metodologia adotados. Consultas públicas foram realizadas a fim de subsidiar uma nova proposta de avaliação, instituída pela Lei n 10.861 (BRASIL, 2004) e conhecida como Sistema Nacional de Avaliação da Educação Superior (Sinaes); sua característica principal foi constituir-se como um sistema que propõe uma perspectiva de trabalho que integra diferentes instrumentos de avaliação.

Ao propor o Sinaes, a CEA não desagregou o caráter regulatório dos processos avaliativos, ao contrário, buscava tornar a educação superior "compatível com as exigências de qualidade, relevância social e autonomia" (BRASIL, 2009. p. 18), mantendo a articulação entre a função formativa e de supervisão da avaliação. Assim, o objetivo da Lei que instituiu - Sinaes é "assegurar o processo nacional de avaliação das instituições de educação superior, dos cursos de graduação e do desempenho acadêmico de seus estudantes" (BRASIL, 2004), cujas finalidades, tal como descritas no $\S 1 .^{\circ}$ do Art. $1^{\circ}$ são: 
A melhoria da qualidade da educação superior, a orientação da expansão de sua oferta, o aumento permanente da sua eficácia institucional e efetividade acadêmica e social e, especialmente, a promoção do aprofundamento dos compromissos e responsabilidades sociais das instituições de educação superior, por meio da valorização de sua missão pública, da promoção dos valores democráticos, do respeito à diferença e à diversidade, da afirmação da autonomia e da identidade institucional (BRASIL, 2004).

É nesse contexto que se institui o Exame Nacional dos Estudantes (Enade) como parte integrante do Sinaes. Segundo o Art. $5^{\circ}, \S 1 .^{\circ}$, o objetivo do Exame é aferir

- desempenho dos estudantes em relação aos conteúdos programáticos previstos nas diretrizes curriculares do respectivo curso de graduação, suas habilidades para ajustamento às exigências decorrentes da evolução do conhecimento e suas competências para compreender temas exteriores ao âmbito específico de sua profissão [...] (BRASIL, 2004).

Ao considerar esse cenário, a Comissão Assessora da Área de Pedagogia do Enade, nomeada pela Portaria no 12, de 10 de janeiro de 2014 , objetiva apresentar suas reflexões acerca da relação entre os conteúdos constantes nas questões do Enade Pedagogia em 2008, 2011 e 2014 e as Diretrizes Curriculares de Formação do Pedagogo, instituídas no ano de 2006. Sendo assim, o foco da análise é relacionar os conteúdos das provas ao ordenamento legal orientador para a formação dos pedagogos. Para alcançar esse objetivo, faremos um breve histórico do curso de Pedagogia no Brasil, em seguida, apresentaremos a proposta documentada nas Diretrizes Curriculares de Formação do Pedagogo. Na sequência, descreveremos a metodologia utilizada nesta pesquisa documental, cujos dados foram tratados pelo software Alceste. Por fim, demonstraremos a análise dos dados coletados à luz dessas diretrizes.

Vale aqui ressaltar que a história do Curso de Pedagogia, bem como as Diretrizes que orientam para a formação do profissional pedagogo convergem para uma perspectiva complexa, tanto de formação quanto de atuação. Então, o posicionamento das análises das reflexões aqui propostas se apoiam em uma compreensão de que os saberes docentes se constituem na intersecção das dimensões teórica e prática, refletidas, e que compõem 
a ação pedagógica. As reflexões também estão sustentadas pela abrangência de atuação do pedagogo que transborda as questões técnicas, mas se ancora em pilares científicos de áreas do conhecimento que compõem a trama complexa da atuação profissional na pedagogia.

Para compreender as análises que realizaremos, é importante destacar que o Enade compõe a avaliação do ensino superior com os demais critérios constituidores do sistema de forma articulada, sendo responsabilidade do Instituto Nacional de Estudos e Pesquisas Educacionais Anísio Teixeira (Inep) que, por sua vez, é um órgão vinculado ao Ministério da Educação (MEC), que cuida das políticas de avaliação da educação básica e da educação superior. Vale ressaltar que, a partir de 2010, quando as Comissões Assessoras de Área (CAA) passaram a elaborar as matrizes de conteúdos, de competências e de habilidades que norteiam a elaboração das questões do Enade, o Banco Nacional de Itens (BNI) foi constituído para comportar as questões elaboradas via editais de chamada pública de docentes.

\section{O CURSO DE PEDAGOGIA NO BRASIL: UM BREVE HISTÓRICO}

O curso de Pedagogia foi criado durante o regime ditatorial do Estado Novo, momento no qual o governo do presidente Getúlio Vargas editou o Decreto-lei no 1.190, de abril de 1939, que instituiu os princípios de organização da Faculdade Nacional de Filosofia vinculada à Universidade do Brasil. Ao estabelecer essa legislação, o ministro da Educação, Gustavo Capanema, buscava operacionalizar a organização da educação nacional, de forma especial, a formação de docentes para atuar na escola secundária.

Esse Decreto, por meio da diretriz intitulada de $3+1$, passou a ordenar o curso de formação dos bacharéis e dos licenciados. O curso foi nominado dessa forma porque abrangia três séries/anos de estudos para a formação dos bacharéis nas diversas áreas do conhecimento - Filosofia, Ciências, Letras e Pedagogia - e uma série/ano de formação na chamada secção Especial de Didática, cujo currículo abarcava as disciplinas de Didática geral, de Didática especial, de Psicologia educacional, de 
Administração escolar e de Fundamentos biológicos e sociológicos da educação. Conhecimentos que, ao serem adquiridos, permitiam que o bacharel fosse titulado como licenciado (BRASIL, 1939). Com essa organização curricular, o curso de Pedagogia, desde a sua gênese, teve dificuldade para definir a sua identidade, bem como a área de atuação dos seus egressos. Silva (2006, p. 50-51) afirma o seguinte:

\begin{abstract}
Introduzido pelo Decreto-Lei n. 1.190/39 simplesmente como pedagogo, sem se fazer acompanhar por alguma referência sobre sua destinação profissional, não se percebia, na época, as ocupações a serem preenchidas por esse novo profissional. As condições do mercado de trabalho também não auxiliavam no equacionamento do assunto. [...] Os anos 1940 e 1950 não deram conta de reverter essa situação tanto que, no início dos anos 1960 , questionava-se, de maneira explícita, a existência do curso de Pedagogia no Brasil. [...] O que se discutia, nesse período, era se o curso de Pedagogia possuía ou não conteúdo próprio. [...] e da pertinência quanto à alocação da preparação de determinados profissionais em educação no curso enquanto tal.
\end{abstract}

Essa dificuldade em definir a identidade, o conteúdo e a função a ser exercida pelo egresso formado no curso de Pedagogia, referida por Silva (2006), foi minorada a partir da promulgação da Lei no 4.024/1961 que instituiu as Diretrizes e Bases da Educação Nacional (LDB/61). Por meio do Art. 70 dessa Lei, os cursos do ensino superior poderiam definir "o currículo mínimo e a duração dos cursos que habilitem à obtenção de diploma capaz de assegurar privilégios para o exercício da profissão liberal serão fixados pelo Conselho Federal de Educação" (BRASIL, 1961).

Essa exigência legal da LDB/61 para a definição do currículo mínimo e das condições de exercício profissional dos cursos de ensino superior levou - Conselho Federal de Educação (CEF) a editar o Parecer n 251/1962 de autoria do conselheiro Raimundo Valnir Cavalcante Chagas (1921-2006). O parecer previa que o bacharelado em Pedagogia deveria formar 0 técnico em educação para exercer as tarefas não docentes e, também, preparar o professor para atuar nas disciplinas pedagógicas do Curso Normal. O mesmo documento, em uma perspectiva prognóstica, apontava que o curso poderia ser estruturado para titular em nível superior os professores que atuariam nos anos iniciais de escolarização. 
A partir da publicação desse parecer, houve um delineamento mais preciso da área de atuação do pedagogo. Essas diretrizes acentuaram a dimensão técnica do trabalho do formado em Pedagogia, mas não equacionaram as críticas feitas pelos estudantes do curso, que consideravam o currículo 'enciclopédico, teórico e generalista'. No entendimento de Silva (2006), essa condição formativa impossibilitava a instrumentalização técnica dos egressos para atuarem, de forma eficaz, no mercado de trabalho educacional.

Essa trajetória que foi, paulatinamente, definindo a história da identidade do profissional de Pedagogia, foi novamente alterada quando se implementaram as políticas educacionais concebidas pelos burocratas vinculados ao regime civil-militar, instaurado com o Golpe Militar de 1964. Essa matriz tecnicista teve início com a publicação do Parecer CFE n 252, de 1969, elaborado pelo professor Raimundo Valnir Cavalcante Chagas. Esse parecer buscava adequar a formação do pedagogo às Leis $n^{\circ}$ 5.540/1968 - Reforma Universitária - e $n^{\circ} 5.692 / 1971$ - Reforma do $1^{\circ}$ e do $2^{\circ}$ graus - que alterou a LDB/61. Essas diretivas do parecer de 1969 apontavam a necessidade de se observar as demandas de formação para o mundo do trabalho, requeridas pela teoria do capital humano ${ }^{8}$ que objetivava preparar o aluno, potencial trabalhador, para ingressar no mercado de trabalho capitalista em desenvolvimento.

Nas orientações do Parecer no 252/1969 do CFE, a formação do pedagogo assumiu uma diretriz metodológica tecnicista e a organização curricular tornou-se fragmentada no intuito de atender a determinados nichos de atuação profissional. Os componentes curriculares deveriam atender às necessidades formativas dos professores que atuariam no ensino normal e nas especialidades de orientação, de administração, de supervisão e de inspeção no âmbito das escolas e dos sistemas escolares. A

\footnotetext{
${ }^{8}$ Para Gaudêncio Frigotto (1999, p. 41, grifo do autor), "O conceito de capital humano - ou, mais, extensivamente, de recursos humanos - busca traduzir o montante de investimento que uma nação faz ou os indivíduos fazem, na expectativa de retornos adicionais futuros. [...] A tese central da teoria do capital humano que vincula educação ao desenvolvimento econômico, à distribuição de renda, configurando-se como uma 'teoria de desenvolvimento' [...]".
} 
partir do momento de consubstanciação dessas diretrizes, configurou-se uma hipertrofia da formação em razão do acréscimo cumulativo de habilitações, bem como pela possibilidade de o pedagogo atuar nas séries iniciais do $1^{\circ} \mathrm{grau}$, desde que determinadas condições fossem atendidas.

Dando continuidade a esse processo de reformulação do curso, em meados dos anos 1970, O CFE editou os pareceres no 67 e $n^{\circ} 68$ de 1975 e $n^{\circ}$ 70 e $n^{\circ} 71$ de 1976, também de autoria do conselheiro Raimundo Valnir Cavalcante Chagas, cujo intento seria continuar a regular e a regulamentar o curso de Pedagogia, buscando resolver questões relativas à identidade profissional e ao campo de atuação do pedagogo. No entanto, esses pareceres foram suspensos logo em seguida pelo ministro da Educação e Cultura (MEC).

Já no ano de 1980, o movimento do MEC para o retorno da edição de pareceres para regulamentar o curso de Pedagogia serviu de indicativo e de estímulo para que os participantes da I Conferência Brasileira de Educação, realizada na Pontifícia Universidade Católica de São Paulo (PUC-SP), indicassem a necessidade de constituir a Comissão Nacional de Reformulação dos Cursos de Formação do Educador (Conarcfe), que atuou até o ano de 1990. Posteriormente, foi substituída pela Associação Nacional pela Formação dos Profissionais da Educação (Anfope) que, conjugada à várias outras entidades de educadores e de estudantes, passou a discutir e a deliberar as diretrizes para a formação dos profissionais da educação (SILVA, 2006).

Os resultados advindos da discussão e da produção intelectual oriunda dos movimentos iniciados nos anos 1980 pelas entidades acadêmicas e profissionais, a exemplo da Anfope, juntamente com as políticas educacionais implementadas após a promulgação da Lei $n^{\circ}$ 9.394/1996, propiciaram o delineamento de certos encaminhamentos relativos às diretrizes de formação dos profissionais formados nos cursos de Pedagogia, no fim do século XX e início do XXI. Como resultado desse processo amplo de discussão, passou-se a defender certos fundamentos que deveriam nortear a conformação dos currículos dos cursos de 
Pedagogia. Podemos citar os seguintes: a criação de uma base curricular comum nacional; a formação docente em Pedagogia vinculada à educação infantil e às séries iniciais do ensino fundamental; o lócus da formação do pedagogo situado de forma preponderante nas universidades e nas faculdades; extinção da dicotomia existente entre a formação do pedagogo e dos demais licenciados e, finalmente, a ideia de que a docência deve ser o eixo fundante da formação.

O fundamento da docência deveria contemplar os seguintes princípios: sólida formação teórica e interdisciplinar sobre o fenômeno educacional e o domínio dos conteúdos; unidade entre teoria e prática, resgatando a práxis da ação educativa; gestão democrática como instrumento de luta pela qualidade do projeto educativo; reforço do compromisso social do profissional da educação; desenvolvimento de um trabalho coletivo e interdisciplinar, propiciando a unidade do trabalho docente; incorporação da concepção de formação continuada, bem como a avaliação permanente dos processos de formação (Anfope, 2001). Tais princípios foram contemplados na Resolução CNE/CP $n^{\circ} 1$, de 15 de maio de 2006, que instituiu as Diretrizes Curriculares Nacionais para o Curso de Graduação em Pedagogia, licenciatura, as quais serão discutidas a seguir.

\section{DIRETRIZES CURRICULARES NACIONAIS DO CURSO DE PEDAGOGIA}

As Diretrizes Curriculares Nacionais para o Curso de Graduação em Pedagogia, licenciatura - Resolução CNE/CP, n ${ }^{\circ} 1$-, aprovadas em 15 de maio de 2006, dispõem, no Art. 2. :

[...] aplicam-se à formação inicial para o exercício da docência na Educação Infantil e nos anos iniciais do Ensino Fundamental, nos cursos de Ensino Médio, na modalidade Normal, e em cursos de Educação Profissional na área de serviços e apoio escolar, bem como em outras áreas nas quais sejam previstos conhecimentos pedagógicos (BRASIL, 2006).

Tal ordenamento legal orienta, por meio do Art. $4 .^{\circ}$, parágrafo único, que as atividades docentes também compreendem a participação na 
gestão e na avaliação dos sistemas e das instituições de ensino em geral, a elaboração, a execução bem como o acompanhamento de programas de atividades educativas.

Com as novas diretrizes, o curso de Pedagogia se constitui como o principal lócus da formação docente dos educadores que atuam na educação básica, incluindo a educação infantil e os anos iniciais do ensino fundamental. A formação dos profissionais da educação no curso de Pedagogia passa a ser reconhecida como um dos requisitos para 0 desenvolvimento da educação básica no país.

Este documento legal repercute os estudos sobre a epistemologia da prática profissional, os quais ampliam sobremaneira a compreensão do ato pedagógico. Schon (1992) ao teorizar sobre os processos de pensamento do profissional professor nos indica que a racionalidade técnica já não dá conta da compreensão da ação pedagógica e que a complexidade do ato pedagógico exige mais do que a racionalidade científica, ou seja, uma racionalidade da prática refletida a partir dos contextos de atuação e suas diferentes dimensões.

A educação do licenciado em Pedagogia deve, pois, propiciar, por meio da investigação, da reflexão crítica e da experiência no planejamento, a execução, a avaliação de atividades educativas, a aplicação de contribuições de campos de conhecimentos, como o filosófico, o histórico, o antropológico, o ambiental-ecológico, o psicológico, o linguístico, o sociológico, o político, o econômico e o cultural. O propósito dos estudos desses campos é nortear a observação, a análise, a execução e a avaliação do ato docente e de suas repercussões ou não em aprendizagens, bem como orientar práticas de gestão de processos educativos escolares e não escolares, além da organização, do funcionamento e da avaliação de sistemas e de estabelecimentos de ensino.

O graduando em Pedagogia deve trabalhar com um repertório de informações e de habilidades composto pela pluralidade de conhecimentos teóricos e práticos, cuja consolidação será proporcionada pelo exercício da 
profissão, fundamentando-se em interdisciplinaridade, em contextualização, em democratização, em pertinência e relevância sociais, em ética e em sensibilidade afetiva e estética. Esse repertório deve constituir-se por meio de múltiplos olhares, a fim de proporcionar uma leitura das relações políticosociais e dos processos educativos por eles desencadeados.

Para a formação do licenciado em Pedagogia, é central o conhecimento da escola como uma organização complexa, cuja função social e formativa é promover, com equidade, educação para e na cidadania. Também é central, para essa formação, a proposição, a realização, a análise de pesquisas e a aplicação de resultados em uma perspectiva histórica, cultural e política, com a finalidade de identificar e de gerir, em práticas educativas, elementos mantenedores, transformadores, geradores de relações sociais que fortalecem ou enfraquecem identidades, reproduzem ou criam novas relações de poder. Além disso, é fulcral a participação na gestão de processos educativos, na organização e no funcionamento de sistemas e de instituições de ensino, almejando uma organização democrática, em que a corresponsabilidade e a colaboração são os constituintes maiores das relações de trabalho e dos poderes coletivo e institucional.

A formação do licenciado em Pedagogia deve estar fundamentada em um trabalho pedagógico realizado em espaços escolares e não escolares, cuja base é a docência. Nessa perspectiva, a docência é compreendida como ação educativa e processo pedagógico-metódico e intencional que não se confunde com a utilização de métodos e de técnicas pretensamente pedagógicos, descolados de realidades históricas específicas.

As atividades docentes também compreendem a participação na organização e na gestão de sistemas e de instituições de ensino, englobando planejamento, execução, coordenação, acompanhamento e avaliação de tarefas próprias do setor da Educação; planejamento, execução, coordenação, acompanhamento e avaliação de projetos e de experiências educativas não escolares; produção e difusão do 
conhecimento científico-tecnológico do campo educacional, em contextos escolares e não escolares.

Enfim, o perfil do graduado em Pedagogia deverá contemplar consistente formação teórica, diversidade de conhecimentos e de práticas, que se articulam, ao longo do curso, nas seguintes dimensões: docência, gestão educacional e produção e difusão do conhecimento.

A estrutura do curso de Pedagogia, respeitando a diversidade nacional e a autonomia pedagógica das instituições, é constituída pelo núcleo de estudos básicos, pelo núcleo de aprofundamento e diversificação de estudos e pelo núcleo de estudos integradores. Tais núcleos deverão proporcionar aos estudantes, concomitantemente, experiências cada vez mais complexas e abrangentes de construção de referências teóricometodológicas próprias da docência, além de oportunizar a inserção na realidade social e laboral de sua área de formação. Por isso, as práticas docentes deverão ocorrer ao longo do curso, desde o seu início.

O projeto pedagógico do curso de Pedagogia deverá contemplar, fundamentalmente, a compreensão dos processos de formação humana e das lutas históricas nas quais se incluem as dos professores, por meio de movimentos sociais; a produção teórica da organização do trabalho pedagógico; a produção e a divulgação de conhecimentos na área da educação que instigue o licenciado em Pedagogia a assumir compromisso social. Nessa perspectiva, é preciso destacar a importância de esses profissionais conhecerem as políticas de educação inclusiva e compreenderem as suas implicações organizacionais e pedagógicas para a democratização da educação básica no país. A inclusão não é uma modalidade, mas um princípio do trabalho educativo. Inclusão e atenção às necessidades educacionais especiais são exigências constitutivas da educação escolar.

Torna-se imprescindível que, durante todo o curso, os estudantes e os seus professores pesquisem, analisem e interpretem os fundamentos históricos, políticos e sociais dos processos educativos; aprofundem e organizem didaticamente os conteúdos a serem ensinados; compreendam, 
valorizem e levem em conta, ao planejar situações de ensino, os processos de desenvolvimento de crianças, de adolescentes, de jovens e de adultos em suas múltiplas dimensões (física, cognitiva, afetiva, estética, cultural, lúdica, artística, ética e biossocial); planejem estratégias visando à superação das dificuldades e dos problemas que envolvem a educação básica.

Em suma, a concepção de trabalho pedagógico escolar e não escolar se fundamenta na docência compreendida como ato educativo intencional e sistemático. O trabalho pedagógico e a ação docente são centrais no processo formativo do licenciado em Pedagogia. Por isso, a formação desse profissional acontece por meio da pesquisa, do estudo e da prática da ação docente e educativa em diferentes realidades. Um curso dessa envergadura exige dos formadores disposição para o efetivo trabalho conjunto e articulado, incentivando, inclusive, a participação dos estudantes no planejamento e na avaliação da execução do projeto pedagógico. Das instituições de ensino, exige-se o compromisso com a produção de conhecimentos para o contexto social nacional, com a construção de projetos educativos comprometidos com o fortalecimento de identidades de estudantes de todas as idades, da identidade de profissionais docentes e da educação brasileira.

É fato que as discussões na construc,ão da base nacional comum para a formac,ão do pedagogo foram acentuadas por ideias difusas, complexas, advindas de diferentes abordagens que cercam as definições do curso e das concepções sobre a cientificidade ou não da Pedagogia. Sendo assim, a partir do exposto até aqui, é possível compreender, especialmente do ponto de vista legal, como o curso de Pedagogia se desenvolveu no Brasil, bem como conhecer, mais profundamente, as diretrizes voltadas a esse curso e a relação destas diretrizes com o processo de avaliação implementado para sua regulação. 


\section{METODOLOGIA DE ANÁLISE}

Para alcançar o objetivo do estudo, foi realizada uma pesquisa documental, de caráter exploratório, cuja fonte primária foram os seguintes documentos oficiais disponíveis nos sites do Inep e do MEC: Diretrizes Curriculares Nacionais para o Curso de Graduação em Pedagogia, licenciatura, Resolução CNE/CP n 1 , de 15 de maio de 2006 e as avaliações do Enade do curso de Pedagogia realizadas em 2008, em 2011 e em 2014.

As provas do Enade começaram a ser aplicadas em 2005 e são realizadas a cada três anos. Para efeitos do estudo aqui proposto, a primeira prova não foi considerada porque é anterior a implementação das Diretrizes instituídas pela Resolução CNE/CP n 1/2006 e a última edição também não se constituiu objeto de análise dessa comissão.

Para proceder com a preparação do corpus a ser analisado, as provas foram salvas em Word e delas foram retiradas as questões de formação geral, as figuras e os gráficos, restando apenas os textos das questões específicas das provas do Enade Pedagogia. O corpus de análise, portanto, é composto por 90 questões, compreendendo as três edições da avaliação. Cada questão foi considerada uma unidade de contexto inicial, submetida à análise lexical pelo Software francês de análise de dados textuais Alceste? (Análise Lexical Contextual de um Conjunto de Segmentos de Texto), versão 4.8/ 2012.

Tal como evidenciado pela IMAGE (2010) o Alceste é um software de análise lexical que utiliza como método a classificação hierárquica descendente, que se dá por meio de sucessivas divisões do texto, identificando oposições entre palavras do texto e extraindo as classes de enunciados representativos.

O Alceste possui um vocabulário próprio que foi utilizado para delinear os procedimentos de análise. O programa utiliza um único arquivo de análise, mas este deve ser organizado a partir de Unidades de Contexto

\footnotetext{
${ }^{9}$ Todos os direitos autorais do software são reservados à Société IMAGE (1986-2000). Autor: Max Reinert.
} 
Iniciais (UCls). Nesta pesquisa, cada uma das 90 questões das provas do ENADE $(2008,2011$ e 2014) representam uma UCI.

Na preparação do corpus para submetê-lo ao programa, é necessária a criação de "linhas com asteriscos" que separam as UCls e são destinadas à identificação da prova e do tipo de questão em análise. Assim, as variáveis selecionadas para identificar cada questão foram as seguintes: o ano de aplicação, o número da questão na prova, se era uma questão de múltipla escolha ou discursiva e, por fim, o tipo da questão.

As questões de múltipla escolha foram classificadas de acordo com o seu objetivo. Sendo assim, há um grupo cujas questões são de asserçãorazão, ou seja, de questões constituídas de duas proposições ligadas pela conjunção 'porque', nas quais os estudantes devem analisar se a segunda é razão ou justificativa da primeira; outras questões são de complementação simples, isto é, o seu enunciado é uma frase incompleta, cuja complementação possível está exposta em uma das alternativas apresentadas; outras são de interpretação - questão que parte de uma situação-problema, a partir da qual os estudantes organizam suas ideias, dados ou informações para resolvê-la - e, por fim, as respostas múltiplas, aquelas em que são apresentadas múltiplas afirmativas para serem analisadas como falsas ou verdadeiras, escolhendo, em seguida, a alternativa que corresponde à análise efetuada.

Nascimento e Menandro (2006) explicam que o software Alceste organiza o discurso a partir do vocabulário, tendo como referência $\circ$ fundamento lexicométrico que distingue "classes de palavras que representam diferentes formas de discurso a respeito do tópico de interesse" (p.74). Além disso, outra operação realizada pelo software é a "lematização", que consiste na substituição de algumas palavras por suas formas reduzidas, o que possibilita ao programa considerar como equivalentes palavras com radicais comuns e que tenham significados aproximados, diferenciando-se apenas em gênero, número ou classe gramatical. 
Nessa pesquisa, pode-se considerar como exemplos de lematizações os seguintes radicais: avalit, estudt, prov+. O corpus da pesquisa foi submetido a uma análise padrão do Alceste que, segundo a Image (2010), possui uma dupla classificação, com vistas a evitar qualquer tipo de influência e com vistas a identificar a consistência da análise.

Em primeiro lugar, foi feita análise de vocabulário, seguida de divisão do texto. Em seguida foi realizada nova classificação para identificar as oposições mais significativas entre as palavras e extrair as classes de enunciados. Em cada classe estão presentes: as palavras e frases mais significativas; os segmentos repetidos; as correspondências das palavras mais características (IMAGE, 2010).

É importante ressaltar que, apesar do Alceste ser um programa de análise quantitativa de dados textuais, seus eixos e classes são nominados qualitativamente a partir do olhar dos pesquisadores sobre os conteúdos dos planos discursivos.

Para Reis (2000), o Alceste oferece informações relevantes acerca do texto, da relação de palavras pertinente a cada classe e como os dados de cada classe se relacionam ao texto como um todo. Cabe, assim, aos pesquisadores a organização e a interpretação dos dados.

De posse dos resultados gerados pelo Alceste, a análise obedeceu ao seguinte processo: (1) Observação da primeira Classificação Hierárquica Descendente (CHD) com vistas a analisar as relações de eixos e classes identificados pelo programa; (2) Seleção das palavras representativas de cada classe, identificadas a partir dos valores do quiquadrado (Phi2), que indica o grau de ligação da palavra com a classe a partir de uma distribuição estatística realizada pelo Alceste; (3) Inserção das palavras representativas no contexto das UCE da classe; (4) Reconstrução dos discursos textuais, a partir da UCE representativas da classe e nominação da classe; (5) Aprofundamento da análise das relações entre as classes e nominação dos eixos.

Vale aqui evidenciar que o software Alceste aplica os princípios do método de Análise de Conteúdo ( $A C$ ), uma vez que este "faz uma ponte 
entre o formalismo estatístico e a análise qualitativa dos materiais" (BAUER, 2002. p. 190). A opção metodológica da pesquisa se dá em função, não só dos procedimentos de coleta de dados selecionados, como também por se acreditar na validade e fidedignidade oferecida por uma análise qualiquantitativa. É pertinente, portanto, adotar a definição de $A C$ de Bardin (1977), uma vez que a mesma consiste em

[...] um conjunto de técnicas de análise das comunicações visandoobter, por procedimentos sistemáticos e objetivos de descrição do conteúdo das mensagens, indicadores (quantitativos ou não) que permitam a inferência de conhecimentos relativos às condições de produção/recepção (variáveis inferidas) destas mensagens (p. 42).

Conforme observa Reinert (1990), na base do funcionamento do programa, está a ideia de relação entre o contexto linguístico e as unidades de contexto. De acordo com Kalampalikis (2003), os procedimentos realizados pelo Alceste visam a organização do discurso analisado em tópicos que revelam as características contidas nos 'mundos lexicais' do corpus textual. Tais procedimentos estão em consonância com os pressupostos da pesquisa documental, uma vez que, nesse tipo de pesquisa, busca-se analisar discursos e conteúdos a partir de "normas sistemáticas de extrair significados temáticos ou os significantes lexicais" (SÁ-SILVA; ALMEIDA; GUINDANI, 2009, p. 11).

Em síntese, o programa gerou um relatório detalhado com a apresentação dos eixos e das classes identificadas por meio da composição do mundo lexical, da lista de palavras mais significativas de cada classe, dos recortes textuais representativos de cada classe, assim como dos gráficos de classificação hierárquica descendentes e das análises fatoriais de correspondência. Após o procedimento de análise pelo software, os pesquisadores procederam a nomeação dos eixos e das classes mediante a análise de seus conteúdos para posterior comparação desses resultados com as diretrizes de formação do pedagogo, constantes na seção a seguir. 


\section{RESULTADOS E DISCUSSÃO}

O corpus analisado, composto por 90 questões ou Unidades de Contexto Inicial (UCI), foi separado, pelo software Alceste, em 463 núcleos de sentido, chamados de Unidades de Contexto Elementar (UCE), agrupando-os em quatro categorias, chamadas de classe, conforme indica a Figura 1.

Figura 1 - Representação das unidades de classe



Fonte: Relatório do Alceste

As classes foram dispostas em dois eixos. O Eixo 1, 'Organização do trabalho didático-pedagógico', agrupa as classes 2, 3 e 4; o Eixo 2, 'Legislação e políticas educacionais', é composto apenas pela classe 1.

A classificação hierárquica descendente (Figura 2) mostra a relação das classes, bem como suas respectivas distribuições nos eixos.

Figura 2 - Classificação Hierárquica Descendente

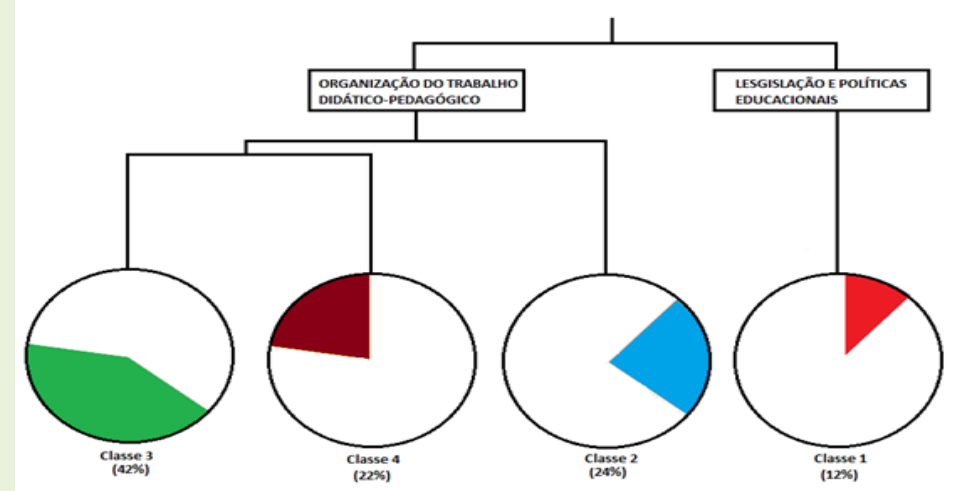

Fonte: Relatório do Alceste 
As classes do Eixo 1 (Classe 3, Classe 4 e Classe 2) remetem a discursos relacionados à organização do trabalho didático-pedagógico, pois tratam, essencialmente, de questões relativas aos conhecimentos da prática pedagógica nos diferentes campos de atuação e às relações da escola com a comunidade, contemplando ainda as questões culturais e de currículo.

A Classe 3, do Eixo 1, primeira apresentada na análise realizada pelo software, é a maior. Ela agrupa $42 \%$ do discurso analisado e apresenta como mais significativa a palavra 'conhecimento'(Phi=.31), que aparece estritamente relacionada às palavras 'cultura' (Phi=.29) e 'tecnologia' (Phi=.26). Elas vêm acompanhadas das palavras 'conteúdo' (Phi=.25), 'currículo'(Phi=.23) e 'disciplina'(Phi=.22). Os enunciados reunidos nessa classe estão relacionados, principalmente, à ideia de cultura e à de currículo, com a preocupação de preparar o sujeito/cidadão para a vida e para a transformação social.

Ao analisar e comparar as questões da prova com o disposto nas Diretrizes Curriculares do curso de Pedagogia - documento base para construir as diretrizes da prova - verificou-se que há coerência do discurso, em especial em relação ao perfil do egresso. Nos termos das Diretrizes, o egresso do curso deve estar apto a

Art. $5^{\circ}[\ldots] \mathrm{VI}$ - ensinar Língua Portuguesa, Matemática, Ciências, História, Geografia, Artes, Educação Física, de forma interdisciplinar e adequada às diferentes fases do desenvolvimento humano;

VII - relacionar as linguagens dos meios de comunicação à educação, nos processos didático-pedagógicos, demonstrando domínio das tecnologias de informação e comunicação adequadas ao desenvolvimento de aprendizagens significativas; (BRASIL, 2006, p.2).

Constatou-se, portanto, que as palavras destacadas pelo software nessa classe remetem às habilidades e às competências requeridas para o egresso nos itens destacados anteriormente, revelando coerência de sentido e pertinência das questões em relação ao perfil de formação do curso. 
$\mathrm{Na}$ análise dos resultados apresentados pelo software, verificou-se, ainda, a relação entre os enunciados presentes no texto das provas e os seguintes conhecimentos que devem ser contemplados na estrutura dos cursos de Pedagogia, conforme orientações presentes nas Diretrizes Curriculares do curso de Pedagogia, no contexto do núcleo de estudos básicos: "d) utilização de conhecimento multidimensional sobre o ser humano, em situações de aprendizagem;" (BRASIL, 2006, p. 3). Assim, pela análise da Classe 3, percebe-se que há coerência entre os elementos presentes na prova e aqueles previstos nas Diretrizes Curriculares para o curso indicando uma formulação dos instrumentos avaliativos direcionados para a complexidade da formação.

A Classe 4, que agrupa $18 \%$ do discurso analisado, traz como palavras mais significativas 'gestão' (Phi=.42) e 'escola' (Phi=.36). Aparecem também, em forte relação com essas palavras, os termos 'atual' (Phi=.32), 'atuação' (Phi=.332), 'participação' (Phi=.30), 'funcionários' (Phi=.28) e 'comunidade' (Phi=.25), sinalizando que, nessa classe, estão reunidos os discursos voltados à gestão, à escola e à comunidade. Os enunciados se relacionam claramente com atividades que competem ao gestor da escola desenvolver com suas equipes pedagógicas, como a construção do Projeto Político Pedagógico da Escola, as relações da escola com a comunidade, a organização curricular e as ações relativas aos conselhos de classe, ampliando o foco de avaliação, tal qual orientam as Diretrizes, e dilatando no exame dos alunos as dimensões da atuação do pedagogo.

Da análise comparativa dessa Classe com o disposto nas Diretrizes Curriculares, verificou-se a coerência entre o conteúdo das questões e as necessidades apontadas para os egressos do curso de Pedagogia, em especial nos itens destacados a seguir:

Art. $5^{\circ}[\ldots]$

VIII - promover e facilitar relações de cooperação entre a instituição educativa, a família e a comunidade;

XII - participar da gestão das instituições contribuindo para elaboração, implementação, coordenação, acompanhamento e avaliação do projeto pedagógico; 
XIII - participar da gestão das instituições planejando, executando, acompanhando e avaliando projetos e programas educacionais, em ambientes escolares e não-escolares (BRASIL, 2006, p. 2).

Na análise das Diretrizes do curso, constatou-se também a coerência entre os elementos presentes na prova - destacados nessa Classe - e os seguintes conhecimentos que integram o núcleo de estudos básicos: "aplicação de princípios da gestão democrática em espaços escolares e não-escolares" (BRASIL, 2006, p. 3). Nessa Classe, portanto, o foco está nos enunciados que discutem os processos da gestão democrática.

A Classe 2, que agrupa $24 \%$ do discurso analisado, é a segunda maior e apresenta a palavra 'professor' (Phi=.40) como a mais importante. Essa palavra está, no centro do discurso, relacionada com as palavras 'turma' (Phi=.32), 'pediu/pede' (Phi=.30), 'criança' (Phi=.30), 'sala' (Phi=.30), 'falar' (Phi=.25), 'aula' (Phi=.23), 'aluno' (Phi=.23), 'escrever' (Phi=.24) e 'situação' $(P h i=.21)$. Nessa Classe, estão concentradas as questões que remetem aos saberes da prática pedagógica. Aqui estão os enunciados que remetem às questões descritas nas provas mediante situações-problema postas nas relações pedagógicas do professor em sala de aula. Uma análise possível de ser realizada a partir da verificação da prevalência da palavra "professor" no discurso, está relacionada à centralidade desta função na prática pedagógica, podendo indicar como base de formulação dos enunciados, um modelo pedagógico diretivo ou mais focado na atuação do professor. (BECKER, 2001)

Entretanto, com a análise dessa Classe, constatou-se coerência com as disposições das Diretrizes Curriculares para o curso de Pedagogia, em relação ao perfil do egresso, em especial nas seguintes competências requeridas:

Art. $5^{\circ}[\ldots]$

II - compreender, cuidar e educar crianças de zero a cinco anos, de forma a contribuir, para o seu desenvolvimento nas dimensões, entre outras, física, psicológica, intelectual, social;

III - fortalecer o desenvolvimento e as aprendizagens de crianças do Ensino Fundamental, assim como daqueles que não tiveram oportunidade de escolarização na idade própria; 
IV - trabalhar, em espaços escolares e não-escolares, na promoção da aprendizagem de sujeitos em diferentes fases do desenvolvimento humano, em diversos níveis e modalidades do processo educativo; $X V$ - utilizar, com propriedade, instrumentos próprios para construção de conhecimentos pedagógicos e científicos (BRASIL, 2006, p. 2-3).

Quanto à estrutura do curso de Pedagogia, as Diretrizes Curriculares indicam, no núcleo de estudos básicos, que parte integrante de tal estrutura deve articular diversos conhecimentos. No Art. $6 .^{\circ}$, verifica-se a coerência de discurso entre o que se exige na legislação com o conteúdo das provas, conforme indicado a seguir:
Art. $6^{\circ}[\ldots]$
e) aplicação, em práticas educativas, de conhecimentos de processos de desenvolvimento de crianças, adolescentes, jovens e adultos, nas dimensões física, cognitiva, afetiva, estética, cultural, lúdica, artística, ética e biossocial;
g) planejamento, execução e avaliação de experiências que considerem $\circ$ contexto histórico e sociocultural do sistema educacional brasileiro, particularmente, no que diz respeito à Educação Infantil, aos anos iniciais do Ensino Fundamental e à formação de professores e de profissionais na área de serviço e apoio escolar;
i) decodificação e utilização de códigos de diferentes linguagens utilizadas por crianças, além do trabalho didático com conteúdos, pertinentes aos primeiros anos de escolarização, relativos à Língua Portuguesa, Matemática, Ciências, História e Geografia, Artes, Educação Física; (BRASIL, 2006, p. 3).

Parece clara a correlação entre os conhecimentos solicitados nas provas e as diretrizes de formação, em especial na seção que apresenta os saberes da prática pedagógica. Nessa Classe, portanto, reúnem-se os enunciados que dão visibilidade ao trabalho docente de sala de aula nos segmentos de ensino compreendidos pela educação básica.

A Classe do Eixo 2 (Classe 1) remete a enunciados relacionados à legislação e a políticas educacionais, trazendo conteúdos relacionados ao reconhecimento, ao estudo e à aplicação das normas em que se consubstanciam as políticas educacionais. Sendo assim, a Classe 1, que é a menor classe e agrupa $12 \%$ do discurso analisado, destaca a palavra 'meta' (Phi=.56) como a mais importante. Ela aparece fortemente relacionada com o 'Índice de Desenvolvimento da Educação Básica (Ideb)' (Phi=.52) e com 
'educação básica' (Phi=.47). São importantes também as palavras 'indicador' (Phi=.34), 'investimento' (Phi=.34) e 'Produto Interno Bruto (PIB)' (Phi=.34). Tais palavras mostram claramente que essa Classe reuniu os trechos das questões que buscavam atestar o conhecimento dos estudantes acerca da legislação vigente no país, especialmente em relação às políticas educacionais.

Assim, é notória, por meio da análise dessa Classe, a coerência entre o conteúdo da prova e os dispositivos presentes nas diretrizes curriculares para o curso, revelando-se, no perfil do egresso (parte integrante das diretrizes), a necessidade de que ele esteja apto a "XVI - estudar, aplicar criticamente as diretrizes curriculares e outras determinações legais que Ihe caiba implantar, executar, avaliar e encaminhar o resultado de sua avaliação às instâncias competentes" (BRASIL, 2006, p. 3), em clara relação com o discurso das provas analisadas.

Da mesma forma, nas diretrizes curriculares, em especial nos dispositivos que tratam do núcleo de estudos básicos, foram identificados os seguintes conhecimentos a serem contemplados na estrutura dos cursos de Pedagogia: "I) estudo, aplicação e avaliação dos textos legais relativos à organização da educação nacional" (BRASIL, 2006, p. 4), coerente, portanto, com o requerido nas provas do Enade em 2008, em 2011 e em 2014.

\section{CONSIDERAÇÕES FINAIS}

A Resolução CNE/CP n 1, de 15 de maio de 2006, instituiu as Diretrizes Curriculares Nacionais para o curso de Pedagogia e definiu "princípios, condições de ensino e de aprendizagem, procedimentos a serem observados em seu planejamento e avaliação, pelos órgãos dos sistemas de ensino e pelas instituições de educação superior do país [...]" (BRASIL, 2006, p.1). Nesses termos, as diretrizes constituem-se em documento orientador aplicável à construção, à implementação e à consolidação dos projetos pedagógicos dos cursos de Pedagogia, em uma perspectiva de direcionamento da 
[...] formação inicial para o exercício da docência na Educação Infantil e nos anos iniciais do Ensino Fundamental, nos cursos de Ensino Médio, na modalidade Normal, e em cursos de Educação Profissional na área de serviços e apoio escolar, bem como em outras áreas nas quais sejam previstos conhecimentos pedagógicos (BRASIL, 2006, p. 4).

Assim, ter nas Diretrizes Curriculares Nacionais para o curso de Pedagogia a referência para a construção das matrizes de avaliação e para as provas propriamente ditas do Enade, é o esperado. É preciso, contudo, analisar de que maneira esse processo ocorre. O documento orientador do currículo serve, de fato, como referência para as avaliações do curso? Em que medida?

Da análise empreendida aqui, restou confirmar tal tese. As últimas três provas do Enade apresentam elementos suficientes para se afirmar que há convergência entre a orientação da formação e a avaliação do curso de Pedagogia. É possível inferir, portanto, que a avaliação, nessa perspectiva, assume importante papel no contexto da política educacional, na medida em que, por meio dela, o Estado pode controlar os processos e as etapas da política e dimensionar seus impactos, legitimando, assim, seus objetivos.

Nessa análise específica, entretanto, verificou-se que algumas habilidades e competências requeridas pelas Diretrizes Curriculares do curso de Pedagogia aparecem com menor frequência ou, ainda, são relegadas nas provas analisadas, já que não se fizerem presentes nas Classes de significação encontradas na análise estatística realizada pelo software Alceste. No que tange ao perfil do egresso, constatou-se, por exemplo, a pouca expressividade das seguintes competências previstas nas diretrizes:

I - atuar com ética e compromisso com vistas à construção de uma sociedade justa, equânime, igualitária;

$\checkmark$ - reconhecer e respeitar as manifestações e necessidades físicas, cognitivas, emocionais, afetivas dos educandos nas suas relações individuais e coletivas;

IX - identificar problemas socioculturais e educacionais com postura investigativa, integrativa e propositiva em face de realidades complexas, com vistas a contribuir para superação de exclusões sociais, étnico-raciais, econômicas, culturais, religiosas, políticas e outras; 
X - demonstrar consciência da diversidade, respeitando as diferenças de natureza ambiental-ecológica, étnico-racial, de gêneros, faixas geracionais, classes sociais, religiões, necessidades especiais, escolhas sexuais, entre outras;

$\mathrm{XI}$ - desenvolver trabalho em equipe, estabelecendo diálogo entre a área educacional e as demais áreas do conhecimento;

XIV - realizar pesquisas que proporcionem conhecimentos, entre outros: sobre alunos e alunas e a realidade sociocultural em que estes desenvolvem suas experiências não escolares; sobre processos de ensinar e de aprender, em diferentes meios ambiental-ecológicos; sobre propostas curriculares; e sobre organização do trabalho educativo e práticas pedagógicas;

$\mathrm{XVI}$ - estudar, aplicar criticamente as diretrizes curriculares e outras determinações legais que Ihe caiba implantar, executar, avaliar e encaminhar o resultado de sua avaliação às instâncias competentes (BRASIL, 2006, p.2-3).

Essa constatação não significa afirmar que tais competências não devem ser trabalhadas nem que são pouco valorizadas e, portanto, não são objeto de avaliação. O que se pode afirmar, pelas análises aqui procedidas, é que as provas analisadas, pela própria dimensão que tomam em um contexto amplo de avaliação de política de formação, não dão conta de testar plena e absolutamente todos os elementos constitutivos da formação.

Da mesma forma, é possível existir uma maior dificuldade em avaliar algumas competências, por meio de uma prova, como "desenvolver trabalho em equipe". Tal dificuldade, ao que parece, está relacionada ao trabalho docente para desenvolver as competências de ordem mais subjetivas (ética e compromisso social), ou que abarcam vertentes mais recentemente requeridas e polêmicas (gênero e escolhas sexuais, faixas geracionais). Ainda fica clara a dificuldade de avaliar, por meio desses exames, atividades que inter-relacionam os diferentes campos do saber (diálogo entre a área educacional e as demais áreas do conhecimento), ou ainda questões que abrangem problemas antigos, mas que a própria sociedade e as autoridades públicas e governamentais não conseguem resolver (exclusões sociais, étnico-raciais, econômicas, culturais, religiosas, políticas; respeito às diferenças de classes sociais, às necessidades especiais etc.).

De qualquer forma, os resultados mostram dados importantes que constituem ganho significativo para a área. Dentre eles, dois ganham 
destaque devido à sua importância, os quais são os seguintes: 1) há um alinhamento do Enade com as diretrizes de formação, o que revela a coerência entre os objetivos propostos pela política avaliativa; 2) fica evidenciado que as provas do Enade são construídas com base em uma matriz cuja referência é o documento que direciona a construção dos projetos pedagógicos dos cursos de Pedagogia (Diretrizes Curriculares Nacionais), revelando-se, portanto, como um instrumento de aferição de condições básicas de oferta e, consequentemente, de garantia de padrão de qualidade. Apesar dos pontos positivos, defendemos que tal instrumento ainda pode evoluir, no sentido de melhor agregar todas as competências exigidas no documento de referência que rege a formação do pedagogo.

\section{REFERÊNCIAS}

ANFOPE. Posicionamento conjunto das entidades ANPED, ANFOPE, ANPAE, FORUNDIR, Cedes e Fórum Nacional em Defesa da formação do professor na reunião de consulta com o setor acadêmico, no âmbito do programa especial "Mobilização Nacional por uma Nova Educação Básica", instituído pelo Conselho Nacional de Educação/CNE, de 7 nov. 2001. Brasília. Disponível em:<http://www.lite.fe.unicamp.br/grupos/formac/docanfope/mobilizacao. $\mathrm{htm}>$. Acesso em: 12 dez. 2018.

BAUER, M. W. Análise de conteúdo clássica: uma revisão. In: BAUER, M. W.; GASKELL, G. (Org.). Pesquisa qualitativa com texto, imagem e som: um manual prático. São Paulo: Vozes, 2002.

BARDIN, L. Análise de Conteúdo. Lisboa: Edições 70, 1977.

BECKER, F. Educação e construção do conhecimento. Porto Alegre: Artmed Editora, 2001.

BRASIL. Decreto-Lei n 1.190, de 4 de abril de 1939. Dá organização à Faculdade Nacional de Filosofia. CLBR, Brasília, 1939. Disponível em: <http://www.planalto.gov.br/CCIVIL_03/Decreto-Lei/19371946/Del1 190.htm>. Acesso em: 12 dez. 2018. .

BRASIL. Lei n 4.024, de 20 de dezembro de 1961. Fixa as Diretrizes e Bases da Educação Nacional. Diário Oficial da União, Brasília, DF, 27 dez. 1961. Disponível em: <http://www2.camara.leg.br/legin/fed/lei/1960-1969/lei-402420-dezembro-1961-353722-publicacaooriginal-1-pl.html>. Acesso em: 12 dez. 2018. 
BRASIL. Constituição da República Federativa do Brasil de 1988. Brasília, DF, 5 out.1988. Disponível em:

<http://www.planalto.gov.br/ccivil_03/Constituicao/Constituicao.htm>. Acesso em: 13 dez. 2018.

BRASIL. Conselho Federal de Educação. Parecer n²51/1962. Regulamenta o currículo mínimo e duração do Curso de Pedagogia. Relator: Valnir Chagas. Documento, n. 11, p. 59-65, 1963.

BRASIL. Lei $n^{\circ} 5.540$ de 28 de novembro de 1968. Fixa normas de organização e funcionamento do ensino superior e sua articulação com a escola média, e dá outras providências. Diário Oficial da União, Brasília, DF, 29 nov. 1968. Disponível em: <http://www2.camara.leg.br/legin/fed/lei/1960-1969/lei-554028-novembro-1968-359201-publicacaooriginal-1-pl.html>. Acesso em: 12 dez. 2018.

BRASIL. Conselho Federal de Educação. Parecer $n^{\circ} 252$, de 11 de abril de 1969. Estudos Pedagógicos Superiores. Mínimos de conteúdo e duração para o Curso de Graduação em Pedagogia. Relator: Valnir Chagas. Documento, n. 100, p. 101-117, 1969.

BRASIL. Lei n 5.692, de 11 de agosto de 1971. Fixa Diretrizes e Bases para o ensino de $1^{\circ}$ e $2^{\circ}$ graus, e dá outras providências. Diário Oficial da União, Brasília, DF, 12 ago. 1971. Disponível em:

<http://www.planalto.gov.br/ccivil_03/LEIS/L5692impressao.htm >. Acesso em: 12 dez. 2018.

BRASIL. Indicação n 67, de 2 de setembro de 1975. Trata dos Estudos Superiores de Educação. Autoria: Valnir Chagas. In: CHAGAS, V. Formação do Magistério: novo sistema. São Paulo: Atlas, 1976. p. 57-77.

BRASIL. Indicação n 70, de 29 de janeiro de 1976. Trata do preparo de Especialistas em Educação. Autoria: Valnir Chagas. In: CHAGAS, V. Formação do Magistério: novo sistema. São Paulo: Atlas, 1976. p. 101-138.

BRASIL. Lei n 9131, de 24 de novembro de 1995. Altera dispositivos da Lei $n^{\circ}$ 4.024, de 20 de dezembro de 1961, e dá outras providências. Brasília, DF, 1995. Disponível em: <http://www2.camara.leg.br/legin/fed/lei/1995/lei-913124-novembro-1995-372496-normaatualizada-pl.html>. Acesso em: 13 dez. 2018.

BRASIL. Lei n 9.394/96, de 20 de dezembro de 1996. Estabelece as diretrizes e bases da Educação Nacional. Diário Oficial da União, Brasília, DF, 23 dez. 1996. Disponível em: <http://www.planalto.gov.br/ccivil_03/Leis/L9394.htm>. Acesso em: 25 maio 2016.

BRASIL. Lei n 10.172, de 9 de janeiro de 2001. Aprova o Plano Nacional de Educação e dá outras providências. Diário Oficial da União, Brasília, DF, 10 jan. 2001. Disponível em: 
<http://www.planalto.gov.br/ccivil_03/leis/leis_2001/l10172.htm>. Acesso em: 12 dez. 2018.

BRASIL. Lei no 10.861, de 14 de abril de 2004. Institui o Sistema Nacional da Avaliação Superior - SINAES e dá outras providências. 2004. Disponível em: <http://www.camara.gov.br/sileg/integras/756047.pdf>. Acesso em: 12 dez. 2018.

BRASIL. Resolução CNE/CP n 1, de 15 de maio de 2006. Institui Diretrizes Curriculares Nacionais para o Curso de Graduação em Pedagogia, licenciatura. Diário Oficial da União, Brasília, DF, 16 maio 2006. Disponível em: < http://portal.mec.gov.br/cne/arquivos/pdf/rcp01_06.pdf>. Acesso em: 12 dez. 2018.

BRASIL. Lei no 13.005 de 25 de junho de 2014. Aprova o Plano Nacional de Educação - PNE e dá outras providências. Diário Oficial da União, Brasília, DF, 26 jun. 2014. Disponível em: <http://www2.camara.leg.br/legin/fed/lei/2014/lei-13005-25-junho-2014778970-publicacaooriginal-144468-pl.html>. Acesso em: 12 dez. 2018.

BRASIL. Ministério da Educação. Instituto Nacional de Estudos e Pesquisas Educacionais Anísio Teixeira. Exame Nacional de Desempenho dos Estudantes (Pedagogia) 2008. Disponível em: <http://download.inep.gov.br/download/Enade2008_RNP/PEDAGOGIA.pdf>. Acesso em: 12 dez. 2018.

BRASIL. Ministério da Educação. Instituto Nacional de Estudos e Pesquisas Educacionais Anísio Teixeira. Exame Nacional de Desempenho dos Estudantes (Pedagogia) 2011. Disponível em: <http://download.inep.gov.br/educacao_superior/enade/provas/201 1/PEDA GOGIA.pdf>. Acesso em: 12 dez. 2018.

BRASIL. Ministério da Educação. Instituto Nacional de Estudos e Pesquisas Educacionais Anísio Teixeira. Exame Nacional de Desempenho dos Estudantes (Pedagogia) 2014. Disponível em: <http://download.inep.gov.br/educacao_superior/enade/provas/2014/36_p edagogia.pdf>. Acesso em: 12 dez. 2018.

FRIGOTTO, G. Educação como capital humano: uma teoria mantenedora do senso comum. IN: FRIGOTTO, G. A Produtividade da Escola Improdutiva: um (re) exame das relações entre educação e estrutura econômico-social capitalista. 5. ed. São Paulo: Cortez. 1999. p. 35-68.

IMAGE. Alceste 2010 Versão Windows: Software de Análise de Dados Textuais. Tolouse, 2010. 46p. Disponível em: <http://www.alcestesoftware.com.br/manuais/alceste-manual.pdf> Acesso em 01 ago. 2013. 
KALAMPALIKIS, N. L'apport de laméthode Alceste dans l'analysedes représentations sociales. In: J. C. Abric (Org.). Méthodes d'étude des représentations sociales. Paris: Érès, 2003. p. 147-163.

NASCIMENTO, A. R. A.; MENANDRO, P. R. M. Análise lexical e análise de conteúdo: uma proposta de utilização conjugada. Estudos e pesquisas em psicologia. UERJ, RJ, Ano 6, N. 2, 2\%/2006. Disponível em:

<http://www.revispsi.uerj.br/v6n2/artigos/pdf/v6n2a07.pdf> Acesso em 23 jul. 2018.

REINERT, M. A. Une Methodlogie d'analyse des donnees textuelles et une application: aurelia de gerard de nerval. Bulletin de Methodologie Socioligique, 1990, n. 26, p. 24-54.

REIS, A. Representações Sociais dos professores sobre a criança problemática. Dissertação (Mestrado em Psicologia) Universidade de Brasília, Instituto de Psicologia, Programa de Pós-graduação em Psicologia, Brasília, 2000.

SÁ-SILVA, J. R.; ALMEIDA, C. D. de; GUINDANI, J. F. Pesquisa documental: pistas teóricas e metodológicas. Revista Brasileira de História \& Ciências Sociais, São Leopoldo, ano. 1, n.1, jul. 2009. Disponível em:

<https://www.rbhcs.com/rbhcs/article/view/6>. Acesso em: 13 dez. 2018.

SCHEIBE, L. Diretrizes curriculares para o curso de pedagogia: trajetória longa e inconclusa. Cad. Pesquisa, São Paulo, v. 37, n. 130, p. 43-62, Apr. 2007. Available from

<http://www.scielo.br/scielo.php?script=sci_arttext\&pid=s0100-

15742007000100004\&lng=en\&nrm=iso>. access on 30 Apr. 2019. http://dx.doi.org/10.1590/S0100-15742007000100004.

SCHÖN, D. Formar professores como profissionais reflexivos. In: NÓVOA, António. (Org.). Os professores e sua formação. Lisboa: Dom Quixote, 1992.

SILVA, C. S. B. da. Curso de Pedagogia no Brasil: história e identidade. 3. ed. Campinas, SP: Autores Associados, 2006.

Recebido em: 19 de dezembro de 2018 Aprovado em: 20 de maio de 2019

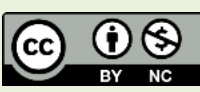

